\title{
Treatment of Alzheimer's disease in Brazil II. Behavioral and psychological symptoms of dementia
}

\author{
Francisco de Assis Carvalho do Vale ${ }^{1}$, Ylmar Corrêa Neto², \\ Paulo Henrique Ferreira Bertolucci $i^{3}$, João Carlos Barbosa Machado ${ }^{4}$, \\ Delson José da Silva ${ }^{5}$, Nasser Allam ${ }^{6}$, Márcio Luiz Figueredo Balthazar ${ }^{7}$ and \\ Group Recommendations in Alzheimer's Disease and \\ Vascular Dementia of the Brazilian Academy of Neurology
}

\begin{abstract}
This article reports the recommendations of the Scientific Department of Cognitive Neurology and Aging of the Brazilian Academy of Neurology for the treatment of Alzheimer's disease (AD) in Brazil, with special focus on behavioral and psychological symptoms of dementia (BPSD). It constitutes a revision and broadening of the 2005 guidelines based on a consensus involving researchers (physicians and non-physicians) in the field. The authors carried out a search of articles published since 2005 on the MEDLINE, LILACS and Cochrane Library databases. The search criteria were pharmacological and non-pharmacological treatment of the behavioral and psychological symptoms of AD. Studies retrieved were categorized into four classes, and evidence into four levels, based on the 2008 recommendations of the American Academy of Neurology. The recommendations on therapy are pertinent to the dementia phase of $\mathrm{AD}$. Recommendations are proposed for the treatment of BPSD encompassing both pharmacological (including acetyl-cholinesterase inhibitors, memantine, neuroleptics, anti-depressives, benzodiazepines, anti-convulsants plus other drugs and substances) and non-pharmacological (including education-based interventions, physiotherapy, occupational therapy, music therapy, therapy using light, massage and art therapy) approaches. Recommendations for the treatment of cognitive disorders of $\mathrm{AD}$ symptoms are included in a separate article of this edition.
\end{abstract}

Key words: Alzheimer's disease, dementia, behavioral and psychological symptoms of dementia, treatment.

Tratamento da doença de Alzheimer no Brasil: II. Dos sintomas comportamentais e psicológicos da demência Resumo - Esse texto apresenta as recomendações da Academia Brasileira de Neurologia, por intermédio do seu Departamento Científico de Neurologia Cognitiva e do Envelhecimento, para o tratamento da doença de Alzheimer (DA) no Brasil, enfocando os sintomas comportamentais e psicológicos da demência (SCPD). Trata-se de uma revisão ampliada das diretrizes publicadas em 2005, resultada de um consenso envolvendo pesquisadores da área, médicos e não médicos. Os autores realizaram uma busca de artigos publicados a partir de 2005 nas bases MEDLINE, LILACS e Cochrane Library. A busca foi direcionada para tratamento farmacológico e não farmacológico dos sintomas comportamentais e psicológicos da DA. Os estudos foram categorizados em quatro classes e as evidências em quatro níveis, com base nas recomendações da Academia Americana de Neurologia publicadas em 2008. As recomendações terapêuticas referem-se à fase demencial da DA. Apresentam-se recomendações para o tratamento dos SCPD, tanto farmacológico (incluindo inibidores da acetilcolinesterase, memantina, neurolépticos, antidepressivos, benzodiazepínicos, anticonvulsivantes e outros

${ }^{1}$ Federal University of São Carlos (UFSCar), Department of Medicine (DMed), São Carlos SP, Brazil; ${ }^{2}$ Federal University of Santa Catarina (UFSC), Department of Internal Medicine, Florianópolis SC, Brazil; ${ }^{3}$ Federal University of São Paulo (UNIFESP), Sector of Behavioral Neurology - Escola Paulista de Medicina, São Paulo SP, Brazil; ${ }^{4}$ Aurus IEPE - Institute of Research and Education on Aging of Belo Horizonte; Faculty of Medical Sciences of Minas Gerais (FCMMG), Department of Geriatric Medicine of Hospital Mater Dei, Belo Horizonte MG, Brazil; ${ }^{5}$ Neurosciences Center of Hospital das Clinicas of the Federal University of Goiás (UFG). Integrated Institute of Neurosciences (IINEURO), Goiânia GO, Brazil. ${ }^{6}$ University of Brasilia (UnB), Laboratory of Neurosciences and Behavior, Brasília DF, Brazil; ${ }^{7}$ University of Campinas (UNICAMP), Faculty of Medical Sciences (FCM), Department of Neurology, Campinas SP, Brazil.

Francisco A.C. Vale - Universidade Federal de São Carlos (UFSCar) / Departamento de Medicina (DMed) - Rod. Washington Luís, Km 235 (SP-310) 13565-905 São Carlos SP - Brazil.

Disclosure: The authors report no conflicts of interest.

Received March 17, 2011. Accepted in final form June 17, 2011.

Vale FAC, et al. Treatment of AD in Brazil: BPSD 
fármacos e substâncias), como não farmacológico (incluindo intervenções educacionais, fisioterapia, terapia ocupacional, musicoterapia, terapia com luz, massagem e arterapia). As recomendações para o tratamento dos transtornos cognitivos da DA são apresentadas em outro artigo desse fascículo.

Palavras-chave: doença de Alzheimer, demência, sintomas comportamentais e psicológicos da demência, tratamento.

\section{Introduction}

In 2005, the Scientific Department of Cognitive Neurology and Aging (DCNCE-ABN) of the Brazilian Academy of Neurology published a set of recommendations and suggestions for the treatment of Alzheimer's disease (AD). ${ }^{1}$ The present report comprises an updated version of these recommendations for treatment of behavioral and psychological symptoms of dementia (BPSD) based on current literature. The recommendations are part of a consensus effort involving a multi-disciplinary group of specialist researchers (physicians and non-physicians) also overseen by the DCNCE-ABN. Recommendations for the treatment of cognitive disorders of $\mathrm{AD}$ symptoms are included in a separate article of this edition.

The authors carried out a search of articles published since 2005 on the MEDLINE (PubMed), LILACS and Cochrane Library databases. The theme was split into two topics for the search: (I) pharmacological treatment, including acetyl-cholinesterase inhibitors (AChEI), memantine, antipsychotics (neuroleptics), benzodiazepines, anti-convulsants, anti-depressives and other drugs (Ginkgo biloba extract, paracetamol, melatonin and testosterone); and (II) non-pharmacological treatment including educational or psycho-educational interventions, rehabilitation/physical activity, occupational therapy, music therapy, physiotherapy, therapy using light, massage, art therapy and aromatherapy.

Studies retrieved were categorized into four classes, and evidence into four levels (See Table), based on the 2008 recommendations by the American Academy of Neurology. ${ }^{2,3}$. A draft of the recommendations was then presented to a panel of researchers from various disciplines (Neurol- ogy, Psychiatry, Geriatrics, Neuropsychology and Speech therapy) for discussion and consensus.

In April 2011, a work group from the American National Institute on Aging and the Alzheimer's Association published recommendations for the diagnosis of dementia due to Alzheimer's disease $e^{4}$ consisting of a revision of the diagnostic criteria for AD published in $1984 .{ }^{5}$ In the same period, the group also published recommendations for the diagnosis of mild cognitive impairment due to $\mathrm{AD}^{6}$ along with recommendations for application in the research setting containing criteria for the so-called "pre-clinical" stages of $\mathrm{AD}^{7}$

The recommendations for treating $\mathrm{AD}$ proposed by the $\mathrm{ABN}$ apply to the dementia phase of the disease, whilst the present studies assessed were based on the definition of probable AD from the 1984 criteria.

This report is organized under two sections (pharmacological treatment and non-pharmacological treatment). With regard to the recommendations related to pharmacotherapy, it should be noted that these are based on scientific studies, whereas the prescribing physician must still check whether the drug is approved by the National Health Surveillance Agency (ANVISA).

\section{Pharmacological therapies Antipsychotics (neuroleptics)}

The term "behavioral and psychological symptoms of dementia" (BPSD) is used to describe a set of non-cognitive symptoms which can manifest in dementia syndromes (e.g. depression, apathy, agitation, hyperactive behavior, sleep disturbances, anxiety, delirium and hallucinations). Identifying BPSD is important since they manifest in the

Table. Level of evidence.
A. Established as effective, ineffective or prejudicial (or establish as useful/predictive or not useful/predictive) for a given condition in the specified population. (Classification level A requires at least two consistent Class I studies)*.
B. Probably effective, ineffective, or prejudicial (and probably useful/predictive or not useful/predictive) for a given condition in the specified population. (Classification level B requires at least one consistent Class I or two Class II studies).
C. Possibly effective, ineffective, or prejudicial (and probably useful/predictive or not useful/predictive) for a given condition in the specified population. (Classification level C requires at least one consistent Class II, or two Class III studies).
U. Insufficient or conflicting data; based on current knowledge, the treatment (trial, prediction) is not proven.

${ }^{*}$ In exceptional cases, a convincing Class I study may suffice for A recommendation if: (1) all criteria are fulfilled, (2) the magnitude of the effect is large (relative degree of better result $>5$ and lower limit of confidence interval $>2$ ). 
majority of individuals with dementia during the course of the base disease (35-75\% of patients). ${ }^{8}$

Individuals with $\mathrm{AD}$ have a greater number of comorbidities, with around $60 \%$ presenting three of more, resulting in the use of several medications. ${ }^{9}$ Drug interactions and polypharmacy may play a major role in the etiology of behavioral disorders seen in some patients with dementia. ${ }^{10}$ A multi-disciplinary team is key to proper management of polypharmacy and rational use of medications. ${ }^{11,12}$

One of the seminal and largest studies on efficacy of neuroleptics, the CATIE-AD, included 421 patients with $\mathrm{AD}$ and psychosis or with agitation/aggressive behavior. Patients were randomly assigned for treatment with a flexible dose of olanzapine, quetiapine, risperidone or placebo for up to 36 weeks. The patients were randomized for treatment with different medicines. Behavioral and psychiatric symptoms, functional abilities, cognition, care needs and quality of life were measured at regular intervals. In the descriptive analysis of the clinical results of these patients in terms of habitual care, some clinical symptoms improved following treatment with atypical anti-psychotics. Antipsychotics are most effective for specific symptoms such as anger, aggressivity and paranoid ideas. Functional abilities, care needs, and quality of life do not appear to improve by treatment with antipsychotics. ${ }^{13}$

A thorough assessment is required encompassing clinical (e.g. infections, constipation, pain), psychiatric (e.g. depression, anxiety), environmental (e.g. ICU) and psychosocial (e.g. abandonment, aggression, change in environment) problems which could be related to the disorder. If possible, the underlying cause should be treated or modified prior to commencing medicamentous treatment, provided this does not pose a safety risk to the patient or caregivers. Thus, before commencing treatment with new medications, check whether the current clinical signs and symptoms are related to behavioral changes such as delirium, pain or an acute clinical condition (e.g. urinary infection, obstipation, pneumonia must be ruled out as a cause of the behavioral changes)..$^{14}$

Neuroleptics may have some utility as maintenance treatment of more severe neuro-psychiatric symptoms, but this benefit must be weighed against potential side effects. Anti-psychotic agents, when indicated, must be reassessed and risk/benefit considered, through continuous assessment. ${ }^{15}$ Monotherapy should first be given using low doses, which should then be steadily escalated until attaining the desired therapeutic effect, a process which may take several weeks. ${ }^{16}$ The antipsychotic should be reduced after behavioral symptoms have been controlled in order to determine whether the treatment is still needed. ${ }^{17,18}$

Upon resolution of BPSD, the antipsychotic can be withdrawn, and in most cases symptoms do not recur. ${ }^{19-21}$ Antipsychotics can have serious side effects such as elevated stroke risk, increased mortality, parkinsonism and cognitive disorders. ${ }^{22-24}$. Earlier recommendations by the American Academy of Neurology suggested the use of antipsychotics only after non-response to treatment with non-pharmacological approaches and optimization with anticholinesterasics and memantine..$^{20,25,26}$

To summarize, considering the information currently available, antipsychotics have a role in treating more severe BPSD associated to dementia, such as delirium and hallucinations, intense agitation and aggressivity, but do not appear to improve functionality, reduce care needs, or improve quality of life in this patient group. After failure of non-pharmacological treatment as a first approach to manage these symptoms, and also use of selective serotonin reuptake inhibitors, anticonvulsants, anticholinesterases and memantine, the lack of safer alternative forces the use of antipsychotics to treat neuropsychiatric symptoms in dementia. Moreover, there is sufficient evidence favoring the use of atypical agents over typical agents, although no specific agent has yet been defined as the drug of choice in the available literature. There is an urgent need for new therapeutic options. Antipsychotic medications are linked to serious adverse events, including increased risk of death, strokes, tardive dyskinesia, malignant neuroleptic syndrome, hyperlipidemia, weight gain, diabetes mellitus, sedations, parkinsonism, and cognitive decline. There are no label indications for the use of neuroleptics in individuals with dementia. Patients and family members must be advised of the potential benefits and risks of antipsychotic agents, particularly mortality risk.

Recommendations - (1) Sufficient evidence exists to recommend antipsychotics for the treatment of psychotic symptoms in moderate to severe Alzheimer's disease (Level B) and for the treatment of agitation and aggressivity (Level A), when other non-pharmacological approaches have failed to promote a response, and after ruling out any other mitigating factors. Treatment should be first administered at low doses, and only after risk/benefit assessment and full discussion with the patient (clinical conditions permitting), family members and caregivers; (2) Atypical neuroleptics should be preferred because they produce fewer side effects and do not pose any greater risk of stroke or death compared to conventional neuroleptics (Level B); (3) Few studies have investigated the repercussions of neuroleptic use beyond 12 weeks but considerable clinical experience supports the practice (Level U). 


\section{Benzodiazepínes}

Benzodiazepines and similar agents can be used for anxiety, insomnia, in cases of acute agitation with increased risk of falls, confusion, memory impairment, respiratory complications which in rare cases can lead to paradoxical disinhibition. Lorazepam and oxazepam, neither of which contains active metabolites, are preferable to agents with long half-lives such as diazepam or clonazepam..$^{16,21,27,28}$

Recommendations - The few specific studies on BPSD in conjunction with data from the literature show modest benefits of benzodiazepine use, and despite a series of adverse effects, indicate that it has a role in the treatment of patients with acute anxiety, with infrequent episodes of agitation or those requiring sedation for a particular procedure such as dental treatment or a diagnostic exam (Level C).

\section{Acetylcholinesterase inhibitors (AChEI)}

A meta-analysis of studies on the efficacy of cholinesterase in the treatment of BPSD in AD has shown a slight beneficial effect. ${ }^{29}$ Using total scores on the Neuropsychiatric Inventory, results of six Class I studies were pooled, assessing metrifonate (three trials on the currently unavailable drug), galantamine (two trials) and donepezil (one trial), giving a total of 2927 patients. The difference in favor of the cholinesterase inhibitors was 1.72 points ( $95 \%$ confidence interval, 0.87-2.57 points) from a possible score of 144 on the NPI.

A systematic review using total scores on the NPI identified four Class I studies of galantamine for the treatment of BPSD in AD. ${ }^{30}$ This beneficial effect was observed after 6 months at a dose of $16 \mathrm{mg} /$ day with a difference in favor of galantamine versus placebo of 2.4 points ( $95 \%$ confidence interval, 0.32-3.84 points) in the cases observed, and 2.1 points ( $95 \%$ confidence interval, $0.16-4.04$ points) in the intention to treat (ITT) cases. At a dose of $24 \mathrm{mg} /$ day, after 6 months of treatment, a difference was seen in favor of galantamine over placebo of 2.09 points ( $95 \%$ confidence interval, 0.34-3.84 points) in the cases observed. The difference in favor of galantamine was mainly due to poorer scores on the NPI among the placebo group (Class I study). ${ }^{31}$

A systematic review identified two Class I studies comparing rivastigmine against placebo, also using total score on the NPI, which reported no difference between the groups. $^{32}$

A systematic review identified four Class I trials comparing donepezil with placebo, using total score on the NPI, which revealed a positive difference in 3 of the studies with a difference of 2.62 points ( $95 \%$ confidence interval $0.43-4.88$ points) in favor of donepezil at $10 \mathrm{mg}$ versus placebo for 24 weeks, and no difference in one study. ${ }^{33}$ Stratified assessments on the NPI identified improvement in specific domains: a Class I study showed a difference on depression/dysphoria and apathy/indifference domains $s^{34,35}$ while another found changes across all domains except elation/euphoria (Class I). ${ }^{36}$ A Class I trial specifically assessing a population with $\mathrm{AD}$ and agitation revealed no benefit from donepezil treatment on the NPI or the CohenMansfield Agitation Inventory (CMAI). ${ }^{37}$

Recommendations - Study results are conflicting regarding the benefits of cholinesterase inhibitors in the treatment of BPSD of AD when assessed using global measures such as total NPI score (Level U). By contrast, there is evidence of benefit (Level A) for the treatment of specific symptoms including depression/dysphoria, anxiety and apathy/indifference. Good clinical practice guidelines recommend maximizing the cholinergic strategy in the management of BPSD in AD.

\section{Memantine}

Pooled data from a systematic review of three Class I studies on the efficacy of memantine for controlling BPSD in moderate to severe $\mathrm{AD}$ revealed benefits of the drug evidenced by a 2.76 point difference on the NPI ( $95 \%$ confidence interval, $0.88-4.63$ points). ${ }^{38}$ This benefit was largely due to worse scores by the placebo group. ${ }^{39}$ Stratified assessment of the NPI showed benefits for agitation/aggression, irritability/lability and nighttime behavior domains. ${ }^{40}$ The evidence indicated that these manifestations occurred less frequently in the treated group, but not that memantine improved preexisting conditions. ${ }^{38}$ This effect was not however, observed In patients with mild to moderate AD..$^{38}$

Recommendations - The use of memantine in patients with moderate to severe $\mathrm{AD}$ probably reduces manifestation of some BPSD (Level B).

\section{Anti-convulsants}

A literature review identified seven randomized studies of anticonvulsants for the treatment of BPSD in demented individuals. Two of these used carbamazepine and five valproic acid. ${ }^{41}$ None of the studies with valproic acid showed any benefit while a small study involving 14 patients actually reported a worsening of agitation/aggression domains on the NPI. Of the carbamazepine studies, one showed no benefits while the other showed improvement on the Brief Psychiatric Rating Scale, although the treated group had more advanced disease than the placebo group, having longer time with the disease (4.0 \pm 5.1 versus $2.8 \pm 2.8$

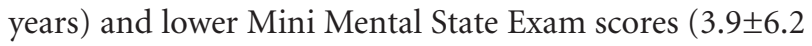


versus $8.3 \pm 7.2$ points), where these disparities compromise evaluation of the result. ${ }^{42}$

Recommendations - The results of the studies assessed remain controversial and are insufficient to indicate the use of anticonvulsants for the treatment of BPSD in $\mathrm{AD}$ (Level U).

\section{Anti-depressives}

A systematic review identified five Class I trials of serotonin reuptake inhibitors in the treatment of agitation in demented individuals. The corresponding meta-analysis revealed benefits on the CMAI ( 0.89 point difference with $95 \%$ confidence interval between $0.57-1.22) .{ }^{43}$ Based on total NPI scores, a Class I study ${ }^{44}$ and two class II studies ${ }^{45,46}$ showed no benefit from sertraline, whereas the study by Finkel et al. ${ }^{46}$ observed improvement in a subgroup of the NPI including dysphoria, irritability, anxiety and agitation/ aggressivity in moderate to advanced AD with BPDS (60\% improvement in treatment versus $40 \%$ in placebo group, $\mathrm{p}=0.006$ ). One Class II study showed benefits from citalopram in the treatment of irritability and depressive mood in individuals with dementia ${ }^{47}$ whereas another Class II study evidenced benefit from citalopram in the improvement of agitation/aggression and lability in demented patients with BPSD on the Neurobehavioral Rating Scale. ${ }^{48}$ Studies with no placebo group comparing trazodone with haloperidol using the $\mathrm{CMAI}^{49}$ and escitalopram with risperidone on the NPI ${ }^{50}$ found similar results for alleviation of BPSD.

The treatment of depression as a comorbidity in $\mathrm{AD}$ was not assessed in this study.

Recommendations - The use of anti-depressives may possibly be beneficial in the treatment of some BPSD in $\mathrm{AD}$ (Level C).

\section{Other drugs and substances}

Class II studies of paracetamol, ${ }^{51}$ testosterone, ${ }^{52}$ and melatonin ${ }^{53}$ showed no benefit, while a Class II study of Ginkgo biloba extract EGb $761^{54}$ and one on latrepirdine, ${ }^{55}$ found a favorable difference in total NPI scores among the treated groups.

Recommendations - The currently available evidence does not allow the recommendation of paracetamol, testosterone, melatonin or Ginkgo biloba for the treatment of BPSD in AD (Level U).

\section{Non-pharmacological therapies}

There is growing interest among researchers in studies involving several forms of non-pharmacological inter- ventions in search of greater levels of evidence through randomized controlled trials. However, many such studies are limited by small samples and the absence of control groups. The investigations also tend to have flawed methodological approaches in as far as they lack in-depth description of the procedures adopted to perform the study. These factors can lead to inconsistent data which in turn limits the reliability of results. However, these drawbacks should not prevent the indication of these treatments, given that studies with reliable levels of evidence have shown good results both in terms of statistical significance and in routine clinical practice.

\section{Education-based interventions}

Randomized controlled trials have shown that educational programs improve BPSD in patients, distress in caregivers, and delay institutionalization while often dispensing with the need to use medications. Moreover, a significantly improved response by caregivers to the behavioral and aggressivity disorders of patients has been noted, along with reduced frequency of these disorders in this patient group. Persistent improvements in depression and agitation have been noted among patients and caregivers as a result of education-based programs and behavioral strategies. ${ }^{56,57}$

\section{Physiotherapy}

Randomized controlled trials have revealed that motor rehabilitation exercises with physical activity and supervised programs of regular exercise can reduce BPSD in patients, as well improve cognition and mood. However, further studies are needed to confirm these findings. ${ }^{58,59}$

\section{Occupational therapy (OT)}

A randomized, controlled trial entailing 10 sessions of OT over 5 weeks was found to promote functional, clinical and behavioral improvement in individuals with dementia, and consequent improvements in quality of life among both patients and caregivers. Patients with severe BPSD however, were excluded from the cited study. ${ }^{60}$ Another study demonstrated improved apathy following OT using a combination of psychomotor activity and music and art therapies. ${ }^{61}$

\section{Music therapy}

Recently, an increasing number of randomized controlled trials based on music therapy have been conducted, showing efficacy in managing BPSD in moderate to severe AD. ${ }^{62}$ Improvements were also seen in depression and apathy, particularly in patients with mild to moderate $\mathrm{AD} .{ }^{63}$

\section{Other treatment approaches}

Therapy using light, massage, aromatherapy, art ther- 
apy among other activities, although demonstrating some degree of effectiveness in a number of trials, lack randomized, controlled evidence-based studies to confirm significant results.

Recommendations - (1) Non-pharmacological strategies may be used for the treatment of BPSD in AD. Educational interventions are recommended (Level B) as well as other treatment strategies including Physiotherapy (Level C), Occupational Therapy (Level C) and Music therapy (Level C). (2) Insufficient evidence is available to recommend light therapy, massage, aromatherapy or art therapy for treating BPSD in AD (Level U).

\section{References}

1. Engelhardt E, Brucki SM, Cavalcanti JL, Forlenza OV, Laks J, Vale FA. Treatment of Alzheimer's disease: recommendations and suggestions of the Scientific Department of Cognitive Neurology and Aging of the Brazilian Academy of Neurology. Arq Neuropsiquiatr 2005;63:1104-1112.

2. Gronseth G, French J. Practice parameters and technology assessments: what they are, what they are not, and why you should care. Neurology 2008;71:1639-1643.

3. French J, Gronseth G. Lost in a jungle of evidence: we need a compass. Neurology 2008;71:1634-1638.

4. McKhann GM, Knopman DS, Chertkow H, et al. The diagnosis of dementia due to Alzheimer's disease: Recommendations from the National Institute on Aging and the Alzheimer's Association workgroup. Alzheimers Dement 2011;7:263-269.

5. McKhann G, Drachman D, Folstein M, Katzman R, Price D, Stadlan EM. Clinical diagnosis of Alzheimer's disease: report of the NINCDS-ADRDAWork Group under the auspices of Department of Health and Human Services Task Force on Alzheimer's Disease. Neurology 1984;34:939-44.

6. Albert MS, Dekosky ST, Dickson D, et al. The diagnosis of mild cognitive impairment due to Alzheimer's disease: Recommendations from the National Institute on Aging and Alzheimer's Association workgroup. Alzheimers Dement 2011;7:270-279.

7. Sperling RA, Aisen PS, Beckett LA, et al. Toward defining the preclinical stages of Alzheimer's disease: Recommendations from the National Institute on Aging and the Alzheimer's Association workgroup. Alzheimers Dement 2011;7:1-13.

8. Apostolova LG, Cummings JL. Neuropsychiatric manifestations in mild cognitive impairment: a systematic review of the literature. Dement Geriatr Cogn Disord 2008; 25:115-126.

9. Fillit HM. The pharmacoeconomics of Alzheimer's disease. Am J Manag Care. 2000;6(22 suppl):S1139-S1144.
10. Buhr GT, White HK. Difficult behaviors in long-term care patients with dementia. J Am Med Dir Assoc 2006;7:180-192.

11. Department of Health and Human Services. Interpretive guidelines for long-term care facilities. State Operations Manual, Appendix PP - Guidance to Surveyors for Long Term Care Facilities. cms.hhs.gov/manuals/downloads/ som107_pp_guidelines_ltcf.pdf. Accessed August 21, 2007.

12. Shekelle P, Maglione M, Bagley S, et al. Comparative effectiveness of off-label use of atypical antipsychotics. Comparative Effectiveness Review No. 6. (Prepared by the Southern California/RAND Evidence-based Practice Center under Contract 290-02-003.) Rockville, MD:Agency for Healthcare Research and Quality; January 2007. Effectivehealthcare.ahrq. gov/repFiles/Atypical_Antipsychotics_Final_Report.pdf.

13. Sultzer DL, Davis SM, Tariot PN, et al. CATIE-AD Study Group. Clinical symptom responses to atypical antipsychotic medications in Alzheimer's disease: phase 1 outcomes from the CATIE-AD effectiveness trial. Am J Psychiatry 2008;165:844-54.

14. Carson S, McDonagh MS, Peterson K. A Systematic Review of the Efficacy and Safety of Atypical Antipsychotics in Patients with Psychological and Behavioral Symptoms of Dementia JAGS 2006;54:354-361.

15. Tran-Johnson TK, Sack DA, Marcus RN, Auby P, McQuade RD, Oren DA. Efficacy and safety of intramuscular aripiprazole in patients with acute agitation: a randomized, double-blind, placebo-controlled trial. J Clin Psychiatry 2007;68:111-119.

16. Grossberg GT, Desai AK. Management of Alzheimer's Disease. J Gerontol 2003;58A:331-353.

17. Cummings JL, Benson DF. Dementia: A clinical approach. (2nd ed.). Boston, MA: Butterworth-Heinemann; 1992.

18. Lyketsos CG, Colenda CC, Beck C, et al. Position statement of the American Association for Geriatric Psychiatry regarding principles of care for patients with dementia resulting from Alzheimer disease. Am J Geriatr Psychiatry 2006;14:561-572.

19. Ballard CG, Thomas A, Fossey J, et al. A 3-month, randomized, placebo-controlled, neuroleptic discontinuation study in 100 people with dementia: the neuropsychiatric inventory median cutoff is a predictor of clinical outcome. J Clin Psychiatry 2004;65: 114-119.

20. Ballard C, Lana MM, Theodoulou M. A randomised, blinded, placebo-controlled trial in dementia patients continuing or stopping neuroleptics (the DART-AD trial). PLoS Med 2008;5:e76.

21. Sink KM, Holden KF, Yaffe K. Pharmacologic treatment of neuropsychiatric symptoms of dementia: a review of the evidence. JAMA 2005;293:596-608.

22. De Deyn PP, Katz IR, Brodaty H, Lyons B, Greenspan A, Burns A. Management of agitation, aggression, and psycho- 
sis associated with dementia: a pooled analysis including three randomized, placebo-controlled double blind trials in nursing home residents treated with risperidone. Clin Neurol Neurosurg 2005;107:497-508.

23. Katz I, de Deyn PP, Mintzer J, Greenspan A, Zhu Y, Brodaty $\mathrm{H}$. The efficacy and safety of risperidone in the treatment of psychosis of Alzheimers disease and mixed dementia: a meta-analysis of 4 placebo controlled clinical trials. Int J Geriatr Psychiatry 2007;22:475-484.

24. Schneider LS, Dagerman KS, Insel P. Risk of death with atypical antipsychotic drug treatment for dementia: metaanalysis of randomized placebo-controlled trials. JAMA 2005;294:1934-1943.

25. Sink KM, Holden KF, Yaffe K. Pharmacological treatment of neuropsychiatric symptoms of dementia: a review of the evidence. JAMA 2005; 293:596-608.

26. Guidelines abstracted from the American Academy of Neurology's dementia guidelines for early detection, diagnosis and management of dementia. AGS Clinical Practice Committee. J Am Geriatr Soc 2003;51:869-873.

27. American Academy for Geriatric Psychiatry. (2005). AAGP Atypical Position Statement. Retrieved March 26, 2008, from http://www.aagponline.org/prof/ antipsychstat_0705.asp.

28. Madhusoodanan S, Shah P, Brenner R, Gupta S. Pharmacological treatment of the psychosis of Alzheimer's Disease: what is the best approach? CNS Drugs 2007;21: 101-115.

29. Trinh N, Hoblyn J, Mohanty S, Yaffe K. Efficacy of cholinesterase inhibitors in the treatment of neuropsychiatric symptoms and functional impairment in Alzheimer disease a meta-analysis. JAMA 2003;289:210-216.

30. Loy C, Schneider L. Galantamine for Alzheimer's disease and mild cognitive impairment. Cochrane Database of Systematic Reviews. In: The Cochrane Library 2011;4: Art. No. CD001747.

31. Cummings JL, Schneider L, Tariot PN, Kershaw PR, Yuan W. Reduction of behavioral disturbances and caregivers distress by galantamine in patients with Alzheimer's disease. Am J Psychiatry 2004;161:532-538.

32. Birks J, Grimley EJ, Iakovidou V, Tsolaki M. Rivastigmine for Alzheimer's disease. Cochrane Database of Systematic Reviews. In: The Cochrane Library 2011; 4: Art. No. CD001191.

33. Birks J, Harvey R. Donepezil for dementia due to Alzheimer's disease. Cochrane Database of Systematic Reviews. In: The Cochrane Library 2011; 4: Art. No. CD001190.

34. Gauthier S, Feldman H, Hecker J, et al. Efficacy of donepezil on behavioral symptoms in patients with moderate to severe Alzheimer's disease. Int Psychogeriatrics 2002;14: 389-404.

35. Feldman H, Gauthier S, Hecker J, et al. Efficacy and safety of donepezil in patients with more severe Alzheimer's disease: a subgroup analysis from a randomized, placebo-controlled trial. Int J Geriatric Psychiatry 2005;20:559-569.

36. Holmes C, Wilkinson D, Dean C, et al. The efficacy of donepezil in the treatment of neuropsychiatric symptoms in Alzheimer disease. Neurology 2004;63:214-219.

37. Howard RJ, Juszczak E, Ballard CG, et al. Donepesil for the treatment of agitation in Alzheimer's disease. N Engl J Med 2007;357:1382-1392.

38. McShane R, Areosa SA, N. M. Memantine for dementia. Cochrane Database of Systematic Reviews. 2011(03): CD003154.

39. Tariot PN, Farlow MR, Grossberg GT, Graham SM, McDonald S, Gergel I. Memantine treatment in patients with moderate to severe Alzheimer disease already receiving donepezil: a randomized controlled trial. JAMA 2004;291:317-24.

40. Cummings JL, Schneider E, Tariot PN, et al. Behavioral effects of memantine in Alzheimer disease patients receiving donepezil treatment. Neurology 2006;67:57-63.

41. Konovalov S, Muralle S, TAmpi RR. Anticonvulsants for the treatment of behavioral and psychological symptoms of dementia: a literature review. Int Psychogeriatrics 2008;20:293-308.

42. Tariot PN, Erb R, Podgorski CA, et al. Efficacy and tolerability of carbamazepine for agitation and aggression in dementia. Am J Psychiatry 1998;155:54-61.

43. Seitz D, Adunuri N, Gill SS, et al. Antidepressants for agitation and psychosis in dementia. Cochrane Database of Systematic Reviews. In: The Cochrane Library 2011; 4: Art. No. CD008191.

44. Weintraub D, Rosenberg PB, Drye LT, et al. Sertraline for the treatment of depression in Alzheimer's disease: week-24 outcomes. Am J Geriatr Psychiatry 2010;18:332-340.

45. Lyketsos CG, DelCampo L, Steinberg M, et al. Treating depression in Alzheimer disease. Arch Gen Psychiatry 2003;60:737-746.

46. Finkel SI, Mintzer JE, Dysken M, et al. A randomized, placebo-controlled study of the efficacy and safety of sertraline in the treatment of the behavioral manifestations of Alzheimer's disease in outpatients treated with donepezil. Int J Geriatric Psychiatry 2004;19:9-18.

47. Nyth AL, Gerhard G. The clinical efficacy of citalopram in treatment of emotional disturbances in dementia disorders: a Nordic multicenter study. Br J Psychiatry 1990; 157:894-901.

48. Pollock BG, Mulsant BH, Rosen J, et al. Comparison of citalopram, perphenazine, and placebo for the acute treatment of psychosis and behavioral disturbances in hospitalized, demented patients. Am J Psychiatry 2002;159:460-465.

49. Suktzer DL, Gray KF, Gunay I, et al. Does behavioral improvement with haloperidol or trazodone treatment depend on psychosis or mood symptoms in patients with dementia? J Am Geriatrics Society 2001;49:1294-1300. 
50. Barak Y, Plopski I, Tadger S, Paleacu D. Escitalopram versus risperidone for the treatment of behavioral and psychotic symptoms associated with Alzheimer's disease: a randomized double-blind pilot study. Int Psychogeriatrics 2011;15:1-5.

51. Chibnall JT, Tait RC, Harman B, Luebbert RA. Effect of acetaminophen on behavior, well-being, and psychotropic medication use in nursing home residents with moderate-tosevere dementia. J Am Geriatrics Society 2005;53:1921-1929.

52. Lu PH, Masterman DA, Mulnard R, et al. Effects of testosterone on cognition and mood in male patients with mild Alzheimer disease and health elderly men. Arch Neurol 2006;63:177-185.

53. Gehrman PR, Connor DJ, Martin JL, et al. Melatonin fails to improve sleep or agitation in a double-blind randomized placebo-controlled trial of institutionalized patients with Alzheimer's disease. Am J Geriatr Psychiatry 2009;17: 166-169.

54. Scripnikov A, Khomeno A, Napryeyenko O. Effects of ginkgo biloba extract EGb 761 on neuropsychiatric symptoms of dementia: findings from a randomized controlled trial. Wien Med Wochenschr 2007;157:295-300.

55. Doody RS, Gavrilova SI, Sano M, et al. Effect od dimebon on cognition, activities of daily living, behavior, and global function in patients with mild-to-moderate Alzheimer's disease: a randomized, double blind, placebo-controlled study. Lancet 2008;372:207-215.

56. Beer CD, Horner B, Almeida OP, et al. Dementia in residential care: education intervention trial (DIRECT); protocol for a randomised controlled trial. Trials 2010;11:63
57. Perry M, DraškoviĆ I, Achterberg T, et al. Can an EASYcare based dementia training programme improve diagnostic assessment and management of dementia by general practitioners and primary care nurses? The design of a randomized controlled trial. BMC Health Serv Res 2008;8:71.

58. Cerga-Pashoja A, Lowery D, Bhattacharya R, et al. Evaluation of exercise on individuals with dementia and their carers: a randomized controlled trial. Trials 2010;11:53.

59. Pitkala KH, Raivio MM, Laakkonen M, Tilvis RS, Kautiainen $\mathrm{H}$, Strandberg TE. Exercise rehabilitation on homedwelling patients with Alzheimer's disease - a randomized, controlled trial. Study protocol. Trials. 2010;11:92.

60. Graff M JL, Vernooil-Dassen MJM, Thijssen M, Dekker J, Hoefnagels WHL, Rikkert MGMO. Community based occupational therapy for patients with dementia and their care givers: randomised controlled trial. BMJ Online First bmj. com. 2006;1-6.

61. Ferrero-Arias J, Goñis-Imízcoz M, Gonzáles-Bernal J, Ortega-Lara F, Silva Gonzales A, Díez-Lopes M. The Efficacy of Nonpharmacological Treatment for Dementia-related Apathy. Alzheimer Dis Assoc Disord 2011;1-7.

62. Raglio A, Bellelli G, Traficante D, et al. Efficacy of Music Therapy in the Treatment of Behavioral and Psychiatric Symptoms of Dementia. Alzheimer Dis Assoc Disord 2008; 22:168-172.

63. Cooke M, Moyle W, Shum D, Harrison S, Murfield J. A Randomized Controlled Trial Exploring the Effect of Music on Quality of Life and Depression in Older People with Dementia. J Health Psychol 2010;15:765-776. 


\section{GROUP RECOMMENDATIONS IN ALZHEIMER'S DISEASE AND VASCULAR DEMENTIA OF THE BRAZILIAN ACADEMY OF NEUROLOGY}

Amauri B. da Silva [UNINEURO, Recife (PE)]; Ana Cláudia Ferraz [Serviço de Neurologia do Hospital Santa Marcelina (SP)]; Analuiza Camozzato de Pádua [Universidade Federal de Ciências da Saúde de Porto Alegre (UFCSPA); Hospital de Clínicas de Porto Alegre (UFRGS) (RS)]; Antonio Lúcio Teixeira [Departamento de Clínica Médica, Faculdade de Medicina da Universidade Federal de Minas Gerais, Belo Horizonte (MG)]; Ayrton Roberto Massaro [Instituto de Reabilitação Lucy Montoro (SP)]; Benito Pereira Damasceno [Departamento de Neurologia da Universidade Estadual de Campinas (SP)]; Carla Tocquer [Universidade Federal do Rio de Janeiro (RJ)]; Carlos Alberto Buchpiguel [Departamento de Radiologia, Faculdade de Medicina da Universidade de São Paulo (SP)]; Cássio Machado C. Bottino [Programa Terceira Idade, Instituto de Psiquiatria do Hospital das Clínicas da Faculdade de Medicina da Universidade de São Paulo (FMUSP) (SP)]; Charles André [Faculdade de Medicina - UFRJ; SINAPSE Reabilitação e Neurofisiologia (RJ)]; Cláudia C. Godinho [Serviço de Neurologia do Hospital de Clínicas de Porto Alegre, Universidade Federal do Rio Grande do Sul (RS)]; Cláudia Sellitto Porto [Grupo de Neurologia Cognitiva e do Comportamento da Faculdade de Medicina da USP (SP)]; Denise Madeira Moreira [Departamento de Radiologia Faculdade de Medicina - UFRJ; Setor de Radiologia - INDC - UFRJ (RJ)]; Eliasz Engelhardt [Setor de Neurologia Cognitiva e do Comportamento - INDC - CDA/IPUB - UFRJ (RJ)]; Elza Dias-Tosta [Presidente da Academia Brasileira de Neurologia, Hospital de Base do Distrito Federal (DF)]; Emílio Herrera Junior [Departamento de Medicina Interna, Faculdade de Medicina de Catanduva (SP)]; Gabriel R. de Freitas [Instituto D’or de Pesquisa e Ensino; Universidade Federal Fluminense (RJ)]; Hae Won Lee [Instituto de Radiologia, Hospital das Clínicas da Faculdade de Medicina da Universidade de São Paulo e Hospital Sírio-Libanês (SP)]; Ivan Hideyo Okamoto [Departamento de Neurologia e Neurocirurgia; Instituto da Memória - Universidade Federal de São Paulo - UNIFESP (SP)]; Jerusa Smid [Grupo de Neurologia Cognitiva e do Comportamento do Hospital das Clínicas da Faculdade de Medicina da Universidade de São Paulo (FMUSP) (SP)]; José Antonio Livramento [Laboratório de Investigação Médica (LIM) 15, Faculdade de Medicina da Universidade de São Paulo (SP)]; José Luiz de Sá Cavalcanti [Departamento de Neurologia - INDC - UFRJ; Setor de Neurologia Cognitiva e do Comportamento - INDC - UFRJ (RJ)]; Letícia Lessa Mansur [Grupo de Neurologia Cognitiva e do Comportamento do Departamento de Neurologia da FMUSP; Departamento de Fisioterapia, Fonoaudiologia e Terapia Ocupacional da Faculdade de Medicina da USP (SP)]; Liana Lisboa Fernandez [Departamento de Ciências Básicas da Saúde, Fundação Universidade Federal de Ciências da Saúde de Porto Alegre (RS)]; Márcia Lorena
Fagundes Chaves [Serviço de Neurologia do Hospital de Clínicas de Porto Alegre, Universidade Federal do Rio Grande do Sul (RS)]; Márcia Radanovic [Laboratório de Neurociências - LIM27, Departamento e Instituto de Psiquiatria da Faculdade de Medicina da Universidade de São Paulo (FMUSP) (SP)]; Maria Teresa Carthery-Goulart [Grupo de Neurologia Cognitiva e do Comportamento do Departamento de Neurologia da Faculdade de Medicina da USP; Centro de Matemática, Computação e Cognição, Universidade Federal do ABC (SP)]; Mônica S. Yassuda [Grupo de Neurologia Cognitiva e do Comportamento do Departamento de Neurologia da Faculdade de Medicina da USP; Departamento de Gerontologia, Escola de Artes, Ciências e Humanidades da USP (EACH/USP Leste) (SP)]; Norberto Anízio Ferreira Frota [Universidade de Fortaleza (UNIFOR), Serviço de Neurologia do Hospital Geral de Fortaleza (HGF) (CE)]; Orestes Forlenza [Laboratório de Neurociências - LIM27, Departamento e Instituto de Psiquiatria da Faculdade de Medicina da Universidade de São Paulo (FMUSP) (SP)]; Paulo Caramelli [Departamento de Clínica Médica, Faculdade de Medicina da Universidade Federal de Minas Gerais, Belo Horizonte (MG)]; Regina Miksian Magaldi [Serviço de Geriatria do Hospital das Clínicas da FMUSP, Centro de Referência em Distúrbios Cognitivos (CEREDIC) da FMUSP (SP)]; Renata Areza-Fegyveres [Grupo de Neurologia Cognitiva e do Comportamento do Hospital das Clínicas da Faculdade de Medicina da Universidade de São Paulo (FMUSP) (SP)]; Renato Anghinah [Grupo de Neurologia Cognitiva e do Comportamento do Hospital das Clínicas da Faculdade de Medicina da Universidade de São Paulo (FMUSP); Centro de Referência em Distúrbios Cognitivos (CEREDIC) da FMUSP (SP)]; Ricardo Nitrini [Grupo de Neurologia Cognitiva e do Comportamento do Hospital das Clínicas da Faculdade de Medicina da Universidade de São Paulo (FMUSP); Centro de Referência em Distúrbios Cognitivos (CEREDIC) da FMUSP (SP)]; Rodrigo Rizek Schultz [Setor de Neurologia do Comportamento do Departamento de Neurologia e Neurocirurgia da Universidade Federal de São Paulo, Núcleo de Envelhecimento Cerebral (NUDEC) - Instituto da Memória (UNIFESP) (SP)]; Rogério Beato [Grupo de Pesquisa em Neurologia Cognitiva e do Comportamento, Departamento de Medicina Interna, Faculdade de Medicina, UFMG (MG)]; Sonia Maria Dozzi Brucki [Grupo de Neurologia Cognitiva e do Comportamento da Faculdade de Medicina da Universidade de São Paulo; Centro de Referência em Distúrbios Cognitivos (CEREDIC) da FMUSP; Hospital Santa Marcelina (SP)]; Tânia Novaretti [Faculdade de Filosofia e Ciências, Campus de Marília, da Universidade Estadual Paulista (UNESP) (SP)]; Valéria Santoro Bahia [Grupo de Neurologia Cognitiva e do Comportamento do Hospital das Clínicas da Faculdade de Medicina da Universidade de São Paulo (FMUSP) (SP)]; 